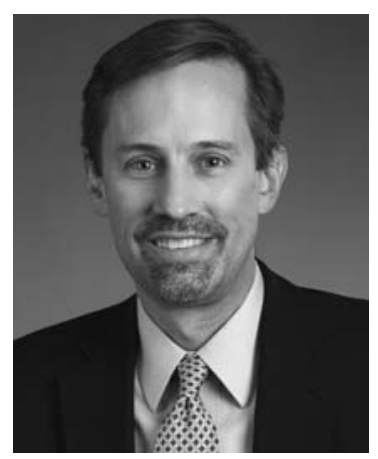

\title{
A Conversation with David Tuveson
}

\author{
Interviewer: Gemma Alderton \\ Senior Editor, Nature Reviews Cancer
}

David Tuveson is Director of the Cancer Therapeutics Initiative and Deputy Director of the Cancer Center at Cold Spring Harbor Laboratory.

Gemma Alderton: Could give us an overview about your work?

Dr. Tuveson: My laboratory studies pancreatic cancer. We are trying to go beyond the "what" of pancreatic cancer to the "why": Why it makes you sick and why the medicines we have don't work. When I started in the field 20 years ago, we didn't understand what caused cancer. Many people investigated the genes of cancer, found mutations that were associated with that cancer, built mouse models to demonstrate that the gene was sufficient to cause the cancer. More recently, mouse models have been used to show that it was necessary for the cancer. At this stage, we now know the "what."

Knowing what causes pancreatic cancer, why is this still a bad disease? Why don't our medicines work better? Why is it that mice and people are sick when they have pancreatic cancer? To answer those questions, my laboratory collaborated with Hans Clevers using a different, tissue-based, model system called "organoids". This has allowed us to ask "why" questions both with mice and with tissue from human patients. The results have been startling.

Gemma Alderton: The development of organoids improves on traditional cell culture approaches, particularly with regard to cancer, because it takes into account the tumor microenvironment.

Dr. Tuveson: The HeLa cells of the ' 50 s were the start for the cancer field. Today, you can grow those types of cultures for many, but not all, cancers. The value of these tissue-based models - be they organoids, conditionally reprogrammed cells, or related approaches - is that you can grow both normal cells and neoplastic cells. There aren't other methods that allow you to grow normal cells beside ones where you have to put in genes to immortalize the cells. Here, you can compare normal cells to tumor cells within the same patient or experimental animal model. That's a huge advantage. Also, our early efforts suggest that you can indeed add in the microenvironment or at least some of the types of cells. We've focused on the cancer fibroblast; we can add that into the epithelial pancreas organoid cultures. We've learned things that we never would have known to look for if we were starting from tissue samples from patients or from mice. I do think that organoids are transformative for the field. We have some exciting new findings as a result of the hard work and excellence of the postdocs and students in my laboratory.

Gemma Alderton: Do the organoids replicate the physiology that you would see within a tissue?

Dr. Tuveson: They approximate it. For the pancreas, you can grow ducts, but not as tubular structures; they actually grow as spheres. Clevers' group and others have shown that, at least in the intestines, you can grow multiple lineages and get mini-guts. In the stomach, you can make glands that produce acid and exotic things of that nature. We have not been able to make an intact pancreas, but that's not the focus of my laboratory. Developmental biologists are pushing those types of questions because in the field of human pancreatic health, diabetes is the main problem. Growing the endocrine cells of the pancreas would potentially be very beneficial for that line of research. We, on the other hand, focus on cancer. We feel that the duct is very much related to the cells that cause at least a majority of types of pancreatic cancer. It would be an exaggeration to say that we are probing physiology deeply. We probe pathophysiology deeply. That, for our purpose, is sufficient.

Gemma Alderton: Can these organoids also be used translationally?

Dr. Tuveson: We can measure things that we couldn't measure before. That's how you discover new genes, new pathways, etc. Using organoids, we can study metabolism differently than you can in two-dimensional culture, and

(C) 2016 Tuveson. This article is distributed under the terms of the Creative Commons Attribution-NonCommercial License, which permits reuse and redistribution, except for commercial purposes, provided that the original author and source are credited. 
the differences between two- and three-dimensional culturing are very evident.

Gemma Alderton: What's the mechanism for that? What causes that difference?

Dr. Tuveson: We don't precisely know. In the three-dimensional organoids, the cells are polarized. There are apical, basal, and lateral surfaces, whereas when you're growing in two dimensions, the cells can't tell up from down or side from side. To survive on plastic you have to be able to proliferate under high tension, which activates many signaling pathways such as the integrins and others. These are cells that are able to exist under harsh conditions. The organoids are less stressful in terms of the actual tension on the cell membrane. I think that the polarization of the cells allows you to look at the pathways as they would exist in vivo. That's a hypothesis we're testing right now.

As for the translational potential of organoids, I'm a cancer doctor. I got into the field because I was trying to think of better ways to help my patients. I spent the last 15 years doing more science than medicine, but with the organoids, we now can identify aspects of pancreatic cancer that are relevant to how we might treat or diagnose the disease that we couldn't examine using cell lines or mice.

For example, you can use organoids to compare normal cells to neoplastic cells in an effort to identify proteins that are expressed specifically in cancer but not by normal tissues. These proteins become "fingerprints" for the cancer. The only normal cells in our system that proliferate are epithelial cells that are dividing because they're developing (as in an embryo) or because they're regenerating in response to trauma. In the pancreas, the trauma would be called pancreatitis. Pancreatitis makes it hard for doctors to figure out if you have a benign or a malignant disease. With the organoids, we can separate that out and very quickly say that these proteins, for example, are in proliferating normal cells (which would only happen in pancreatitis), whereas those proteins are in proliferating cancer cells. By using such comparisons, we could very rapidly distinguish between the two. This very talented scientist in my lab, Dannielle Engle, has used this approach to identify proteins that she thinks are potential biomarkers specific for pancreatic cancer. When she looks for those proteins in the blood of humans who either do or do not have pancreatic cancer, she's diagnosed correctly, I think, 10 out of 11 times. Even from a skeptical standpoint, you have to be encouraged that we can see deeply into problems that we couldn't before.

The other obvious question is whether you could use the organoids to personalize therapies. Could you use it to choose the medicine that might help a patient? A team of workers in my laboratory has taken that approach. We're in the early stages, but so far they've identified a few therapies that look active in the animal models. The organoids appear to be putting us on the right track.

The organoid system has also allowed us to study the microenvironment and the interaction between the cells in the stroma of the tumor as they communicate with the epithelial cells. The tumor microenvironment team in our laboratory has identified a type of stromal cell: a version of a fibroblast that's never been reported and has the right characteristics of something that might promote cancer in a significant way.

Gemma Alderton: There seems to be a controversy as to whether the microenvironment is protective versus promoting in pancreatic cancer. Could you comment on that?

Dr. Tuveson: Think of pancreatic cancer as an oatmeal cookie with raisins in it. The raisins are the cancer cells, and the oatmeal dough is the stroma. There's more dough than there are raisins. We found some time ago that the stroma made it difficult for the vasculature to both develop and function. We hypothesized that because of this, we couldn't deliver drugs into the tumor. When we used various methods to lessen the stroma, the drugs could get in better. In mouse models, it appeared that would be beneficial. You could kill more cancer cells and the mice would live longer. However, this idea did not translate well to the clinic. In fact, the patients did worse when the stromal ablation approach was taken with the hedgehog inhibitor.

The dissatisfying part of that was that, as is true of many clinical trials, there was no real scientific angle to the trial. Biopsies were not taken. There was no scientist with an eye on the trial. In the end, when they wanted my advice, I asked them "What do the biopsies show?" They said "What biopsies?" It's frustrating for scientists to see our work not tested properly in the clinical setting.

Nevertheless, we hadn't lost sight of the fact that it failed in the humans even though it looked promising in mice. The organoid coculture allowed us to go back and ask why this happened. We think now that this other type of fibroblast could partially explain why things got rocky for the patients. That's our hypothesis based on the data we have available to us right now. We don't think that the stroma is a friend in this. It clearly can regulate the differentiation of the cancer cells, and well-differentiated tumors tend to behave differently than undifferentiated tumors. The hedgehog inhibitor trials made it difficult for the well-differentiated cancers to persist, so you selected for a type of carcinoma that was less differentiated, but we think that was only part of it. The other part was that the type of fibroblast you were left with was one that would promote cancer much worse than the first type.

Gemma Alderton: How would you better do that clinical trial in the future?

Dr. Tuveson: As both a physician and a basic scientist, I feel that we have an obligation to perform early-phase clinical trials - so-called phase 0 trials - on the first few patients treated with a new medicine or evaluated with a new diagnostic technique. These are trials where the end points are molecular and scientific, where there are still the safeguards for the patients' well-being, but the doses of drugs used are limited and the time periods of the experiment are short. Phase 0 trials aren't generally per- 


\section{A CONVERSATION WITH DAVID TUVESON}

formed for several reasons, the main one being that academic centers don't have such facilities. The second one being that the pharmaceutical companies who are our friends in developing new medicines don't have the patience to conduct these studies nor the bankroll to support them. What we're getting better at, though, is convincing the funding agencies that such studies are important.

I'm hopeful that basic scientists can become part of the early-phase clinical trails process, working with physicians to help interpret the early data. At Cold Spring Harbor, we feel that if we could design these phase 0 studies in a medical setting where you could have, if need be, 24/7 monitoring, you could learn in a few hours or a few days whether or not you were on the right track for most therapies and diagnostics, even immunotherapies. That's our hope. The organoids are expected to be the ex vivo part of this process, but we also need to do in vivo phase 0 studies. When you study a disease where its mortality rate is about equal to its incidence, you're in the red zone. You can try to kick field goals all day long, but you'll never win anything. We have to change our approach. We have to be aggressive, not complacent. 


\section{$\$_{\text {CSH\& }}^{\infty}$ Cold Spring Harbor Symposia SYMPOSIA On Quantitative Biology}

\section{A Conversation with David Tuveson}

Cold Spring Harb Symp Quant Biol 2016 81: 341-343 originally published online December 8, 2016

Access the most recent version at doi:10.1101/sqb.2016.81.031310
Creative This article is distributed under the terms of the
Commons http://creativecommons.org/licenses/by-nc/4.0/, which permits reuse and
License redistribution, except for commercial purposes, provided that the original author and source are credited.

Email Alerting Receive free email alerts when new articles cite this article - sign up in Service the box at the top right corner of the article or click here. 